\title{
CONTROLE DA COCHONILHA DE ESCAMA DA PALMA FORRAGEIRA COM O USO DE EXTRATO DE NIM
}

António Oliveira Nhaga $^{1}$, Ciro de Miranda Pinto ${ }^{2}$, Maria Gorete Flores Salles ${ }^{3}$, Olienaide Ribeiro de Oliveira Pinto ${ }^{4}$, Francisco Acácio de Sousa ${ }^{5}$

${ }^{1}$ Discente do curso de Agronomia da Universidade da Integração Internacional da Lusofonia Afro-Brasileira (UNILAB), Redenção-CE, Brasil.

${ }^{2}$ Professor Doutor do curso de Agronomia da UNILAB, Redenção-CE, Brasil. E-mail: ciroagron@unilab.edu.br

${ }^{3}$ Professora Doutora do curso de Agronomia da UNILAB, Redenção-CE, Brasil.

${ }^{4}$ Professora Doutora no Mestrado Acadêmico em Sociobiodiversidade e Tecnologias

Sustentáveis (MASTS) da UNILAB, Redenção-CE, Brasil.

${ }^{5}$ Eng. Agrônomo, mestrando no Mestrado Acadêmico em Sociobiodiversidade e Tecnologias Sustentáveis (MASTS) da UNILAB, Redenção-CE, Brasil

Recebido em: 22/09/2018 - Aprovado em: 23/11/2018 - Publicado em: 03/12/2018 DOI: 10.18677/EnciBio_2018B28

\section{RESUMO}

A palma forrageira apresenta grande potencial produtivo sendo usada na alimentação humana e animal, produção de medicamentos, cosméticos, corantes e na conservação e recuperação de solos. No entanto, apresenta diversas pragas, que causam danos e prejuízos como a Diaspis echinocacti (Hemiptera, Diaspididae), conhecido vulgarmente como Cochonilha de escamas. Assim, objetivou-se definir a concentração de extrato de nim que proporcione o controle da cochonilha de escama na palma forrageira graúda. O trabalho foi conduzido no município de Barreira, Ceará. Utilizou-se 5 tratamentos com extratos de nim, sendo: 0, 50, 100, 150 e $200 \mathrm{~g} / 1000 \mathrm{~mL}$ de água na parcela primária e 4 tratamentos na parcela secundária com quatro repetições. O ajustamento da regressão foi o polinomial quadrático a $5 \%$ de probabilidade, tendo coeficiente de determinação $R^{2}$ de $75,69 \%$. O valor da dose ótima foi $77,07 \mathrm{~g}$ de nim por $1000 \mathrm{~mL}$ de água o que resultou um percentual de área da raquete quaternária infestada por cochonilha de escama máxima de $18,78 \%$, depois desse nível ocorrem decréscimos do percentual de área infestada. O extrato aquoso de $200 \mathrm{~g}$ nim em pó para $1000 \mathrm{~mL}$ de água proporcionou maior controle da cochonilha de escama na palma forrageira graúda.

PALAVRAS-CHAVE: Diaspis echinocacti, Opuntia ficus-indica Mill, Semiárido, Sustentabilidade

\section{NIM EXTRACT FOR THE CONTROL OF THE SCALE COCHINEAL IN THE CACTUS PEAR FORAGE}

\begin{abstract}
The forage palm presents great productive potential being used in human and animal feeding, production of medicines, cosmetics, dyes and in the conservation and recovery of soils. However, it exhibits several pests, which cause damages and losses, such as Diaspis echinocacti (Hemiptera, Diaspididae), commonly known as Cochineal in scales. The objective of this study was to define the concentration of neem extract that provides control of scale cochineal in the tall forage palm. The
\end{abstract}


work was conducted in the town of Barreira, Ceará. Five treatments with neem extracts were used: $0,50,100,150$ and $200 \mathrm{~g} / 1000 \mathrm{~mL}$ of water in the primary plot and 4 treatments in the secondary plot with four replicates. The regression adjustment was the quadratic polynomial at $5 \%$ probability, with coefficient of determination $\mathrm{R}^{2}$ of $75.69 \%$. The value of the optimum dose was $77.07 \mathrm{~g}$ of neem per $1000 \mathrm{~mL}$ of water, which resulted in a percentage of area of the infested quaternary racket with a maximum scale of $18.78 \%$, after which level there is a decrease in the percentage of infested area. The aqueous extract of $200 \mathrm{~g}$ neem powder for $1000 \mathrm{~mL}$ of water provided greater control of scale cochineal in the tall forage palm.

KEYWORDS: Diaspis echinocacti, Opuntia ficus-indica Mill, Semiarid, sustentability

\section{INTRODUÇÃO}

A região semiárida do Nordeste brasileiro apresenta precipitação pluvial média anual de 400 a $700 \mathrm{~mm}$, temperatura média de $28^{\circ} \mathrm{C}$, umidade relativa de 50 a $60 \%$, evaporação de $2.548 \mathrm{~mm}$ (OLIVEIRA, 2014). As plantas xerófilas destacamse pela tolerância a seca. A palma forrageira Opuntia fícus-incidica L (Mill) tem contribuído para o desenvolvimento socioeconômico do semiárido brasileiro, por ser uma cultura adaptada às condições climáticas da região. Nesse cenário, a produção de palma forrageira é uma das estratégias de apoio à convivência da pecuária regional com a seca (CAVALCANTE et al., 2014), pois é considerada fonte energética de grande potencialidade para a nutrição de ruminantes como bovinos, caprinos e ovinos, tanto na forma in natura ou desidratada (SILVA et al., 2014).

Vários são os fatores que podem influenciar na produtividade da palma forrageira: fertilidade do solo, pluviosidade, densidade de plantio, vigor das mudas, ataque de pragas e doenças, dentre outros. Nesse contexto, a palma forrageira representa uma opção de importância para os criadores sertanejos, por sua alta eficiência no uso da água, alta produtividade, excelente qualidade como alimento energético de alta digestibilidade, e, além disso, constitui-se em estratégica reserva hídrica para os rebanhos, sendo importante ferramenta no manejo e proteção do solo (LIMA et al., 2015).

O emprego de extratos vegetais pode ser considerado como um manejo promissor na proteção das plantas. Além de auxiliar na diminuição das doses e frequência de aplicação de agroquímicos sintéticos, danosos a saúde humana e ao meio ambiente (SANTOS et al., 2013). Uma das espécies mais utilizadas para obtenção de extratos é o nim (Azadirachta indica $A$. Juss), planta que possui alguns compostos químicos, sendo o principal é a azadiractina, presente em folhas e frutos (MARTINEZ, 2002). O extrato de nim tem sido utilizado para controlar o crescimento inicial de plantas daninhas (ALBURQUEQUE et al., 2015), controle pragas em grãos armazenados como o milho (BORSONARO et al., 2013), controle da mosca minadora (Liriomyza sativae) meloeiro (COSTA et al., 2016), controlando pulgão nos cultivos de brócolis (VIERA; PERES, 2017). Outros inseticidas apresentam potencial no controle de cochonilhas, a exemplo, extratos aquosos de pinhão-manso (HOLTZ et al., 2016), Capsicum frutescens L., associada ao álcool, fumo em rolo e sabão de coco (BRAGA et al., 2017), pimenta do reino (Piper nigrum) com adição de sabão de coco, álcool e água (LOUREIRO et al., 2016).

Neste sentido, estudos que ampliem a possibilidade do uso de inseticidas botânicos são promissores e podem auxiliar no manejo de pragas em diversos sistemas agrícolas. Assim, o objetivo deste trabalho foi definir a concentração de extrato de nim que proporcione controle da cochonilha de escama na palma forrageira graúda. 


\section{Área experimental}

\section{MATERIAL E MÉTODOS}

A pesquisa foi conduzida durante os meses maio a julho de 2016, na fazenda Bom Sucesso, situada no município de Barreira-CE, cujas coordenadas

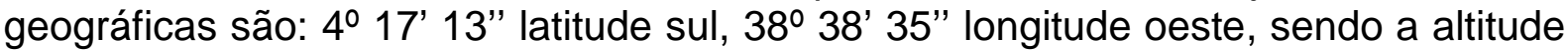
local de $83,5 \mathrm{~m}$. O clima é classificado como tropical quente semiárido brando, com o índice de pluvisiovidade de $1.061,9 \mathrm{~mm}$, temperatura média anual de $26^{\circ}$ a $28^{\circ} \mathrm{C}$ (IPECE, 2017).

O experimento foi instalado em uma área cultivada com palma graúda $(O$. ficus indica Mill), onde foram marcadas as raquetes de ordem quaternária para aplicação do extrato de nim ( $A$. indica) produzido a partir de folhas previamente trituradas em forrageira até a forma de pó. Posteriormente foram pesadas em balança digital e separadas em porções de 50,100,150 e 200 ge extrato de nim.

\section{Delineamento experimental}

O delineamento utilizado foi o inteiramente casualizado em um esquema de parcela subdivida com 5 tratamentos na parcela principal (extratos de $\mathrm{Nim} \mathrm{0,50,}$ 100,150 e $200 \mathrm{~g} / 1000 \mathrm{~mL}$ de água) e 4 tratamentos na parcela secundária (tempo de aplicação) e quatro repetições (Figura 1).
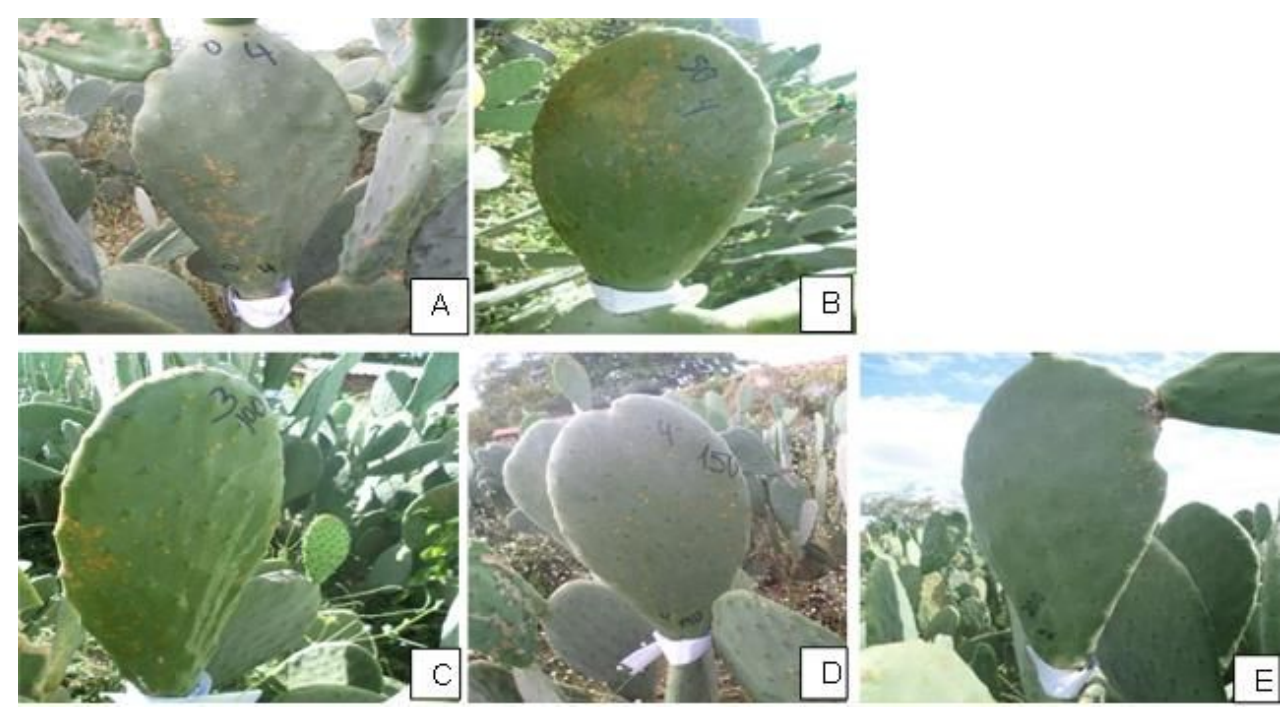

FIGURA 1. (A) - Extrato controle (água); (B) - $50 \mathrm{~g}$ nim picado/1000mL água; (C) $100 \mathrm{~g}$ nim em picado/1000mL água; (D) - $150 \mathrm{~g}$ nim em picado/1000mL água e (E) $200 \mathrm{~g}$ nim em picado/1000mL água.

A primeira aplicação do extrato de nim e avaliação por foto foram realizadas em 27 junho, a segunda avaliação por foto em 4 de julho, a terceira avaliação por foto foi realizada em 11 de julho e a quarta avaliação por foto foi realizada em 18 de julho.

A avaliação da eficiência da aplicação do extrato de Nim, foi realizada com uso das fotos das raquetes de palma forrageira. As imagens das raquetes quartanárias da palma forrageira foram obtidas com uma máquina fotografia digital SAMSUNG modelo SMART CAMERA DV150F. As imagens foram descarregadas no notebook para determinar o percentual de área infestada por de cochonilha de escama com emprego do software APS ASSESS 2.0 (LAMARI, 2008). A Figura 2 ilustra a utilização software APS ASSESS 2.0 na determinação do percentual de área afetada em relação à área total da raquete quaternária. 


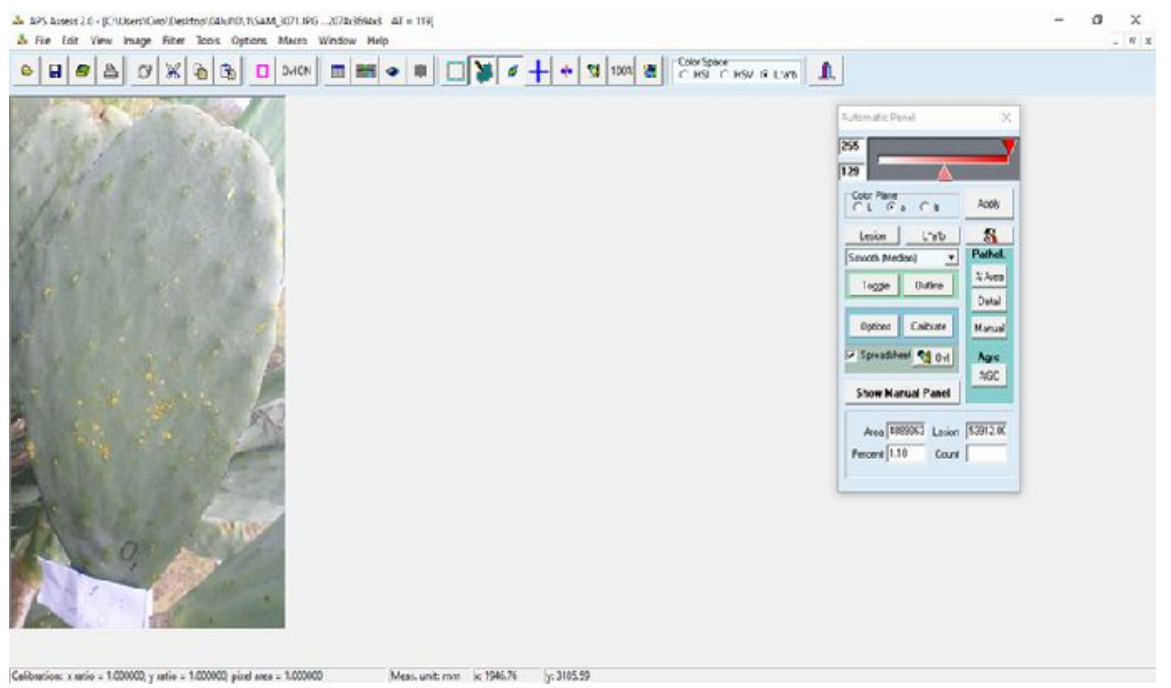

FIGURA 2. Software APS ASSESS 2.0.

\section{Análise estatística}

Os dados foram submetidos à análise de variância e, quando detectada ou não a significância pelo teste $\mathrm{F}$ a $1 \%$ ou $5 \%$ de probabilidade, as médias dos tratamentos qualitativos foram comparadas pelo teste de Tukey ao nível de $5 \%$ de probabilidade. Para dados quantitativos empregou-se a análise de regressão para verificar o efeito das doses de nim no controle da cochonilha. Para tanto, utilizou-se - ASSISTAT 7,7 betas, Sistema de Análise Estatística da UFCG (SILVA; AZEVEDO, 2016).

\section{RESULTADOS E DISCUSSÃO}

O resumo da análise de variância do experimento em parcelas subdivididas consta na Tabela 1. A interação entre Fator 1 x Fator 2, não foi significativa ao nível de $5 \%$ de probabilidade, revelando independência entre esses fatores para percentual de área de raquete quaternária infestada por cochonilha. Isolando-se o fator dias de avaliação, constatou-se a existência de efeito significativo a $1 \%$ de probabilidade.

TABELA 1- Quadrado médio da área de raquete quaternária infestada por cochonilha de escama, Barreira - CE, 2016.

\begin{tabular}{|c|c|c|}
\hline Fontes de variação & GL & Quadrado Médio \\
\hline Fator $_{1}$ (Doses do extrato de nim) & 4 & $162,24^{--}$ \\
\hline Resíduo (a) & 15 & 62,17 \\
\hline Parcela & 19 & \\
\hline Fator $_{2}$ (Dias de avaliação) & 3 & 555,67 \\
\hline Interação Fator 1 x Fator 2 & 10 & $10,52^{\mathrm{ns}}$ \\
\hline Resíduo (b) & 45 & 13,66 \\
\hline Total & 79 & - \\
\hline $\mathrm{CV}_{\mathrm{a}}(\%)$ & 48.62 & \\
\hline $\mathrm{CV}_{\mathrm{b}}(\%)$ & 22.79 & \\
\hline $\begin{array}{l}\text { Fator }{ }_{1} \text { : parcela principal doses de extrat } \\
\text {-- Os tratamentos são quantitativos. O T } \\
\text { ** significativo ao nível de } 1 \% \text { de probab } \\
\text { ns não siqnificativo }(p \geq 0.05)\end{array}$ & $\begin{array}{l}\text { período } \\
\text { a. }\end{array}$ & iação \\
\hline
\end{tabular}


A análise de variância da regressão para área de raquete quaternária infestada por cochonilha de escama (Tabela 2) em função das doses extrato aquoso de $\operatorname{nim}(0 ; 50 ; 100 ; 150$ e $200 \mathrm{~g} \mathrm{nim} / 1000 \mathrm{~mL}$ de água), teve ajustamento ao modelo polinomial quadrático, significativo ao nível de $5 \%$ de probabilidade (Tabela 2 ), tendo coeficiente de determinação o $\mathrm{R}^{2}$ de $75,69 \%$ (Figura 3).

TABELA 2- Quadrado médio para área percentual da raquete quaternária infestada por cochonilha, Barreira - CE, 2016.

\begin{tabular}{lcc}
\hline Fontes de Variação & GL & QM \\
\hline Regressão Linear & 1 & $197,5931^{\text {ns }}$ \\
Regressão Quadrática & 1 & $293,6205^{*}$ \\
Regressão Cúbica & 1 & $0,20094^{\text {ns }}$ \\
Regressão Quártica & 1 & $157,5622^{\text {ns }}$ \\
\hline Total & 4 & GL-resíduo $=15$ \\
\hline
\end{tabular}

${ }^{*}$ significativo ao nível de $5 \%$ de probabilidade $(0,01 \leq \mathrm{p}<0,05)$.

${ }^{n s}$ não significativo $(p \geq 0,05)$.

O valor da dose ótima foi de $77,07 \mathrm{~g}$ de nim por $1000 \mathrm{~mL}$ de água, resultando em um percentual de área de raquete quaternária infestada por cochonilha máxima de 18,78 \% (Área infestada por cochonilha/Área da raquete quaternária total), depois desse nível ocorrem decréscimos do percentual de área infestada. Silva et al. (2013), em estudo realizado por questionário no interior do município de Santo André - PB, com produtores de palma forrageira, constataram que o controle da cochonilha-do-carmim, foi realizado com produtos caseiros como gás, óleo, sabão em pó e detergente neutro.

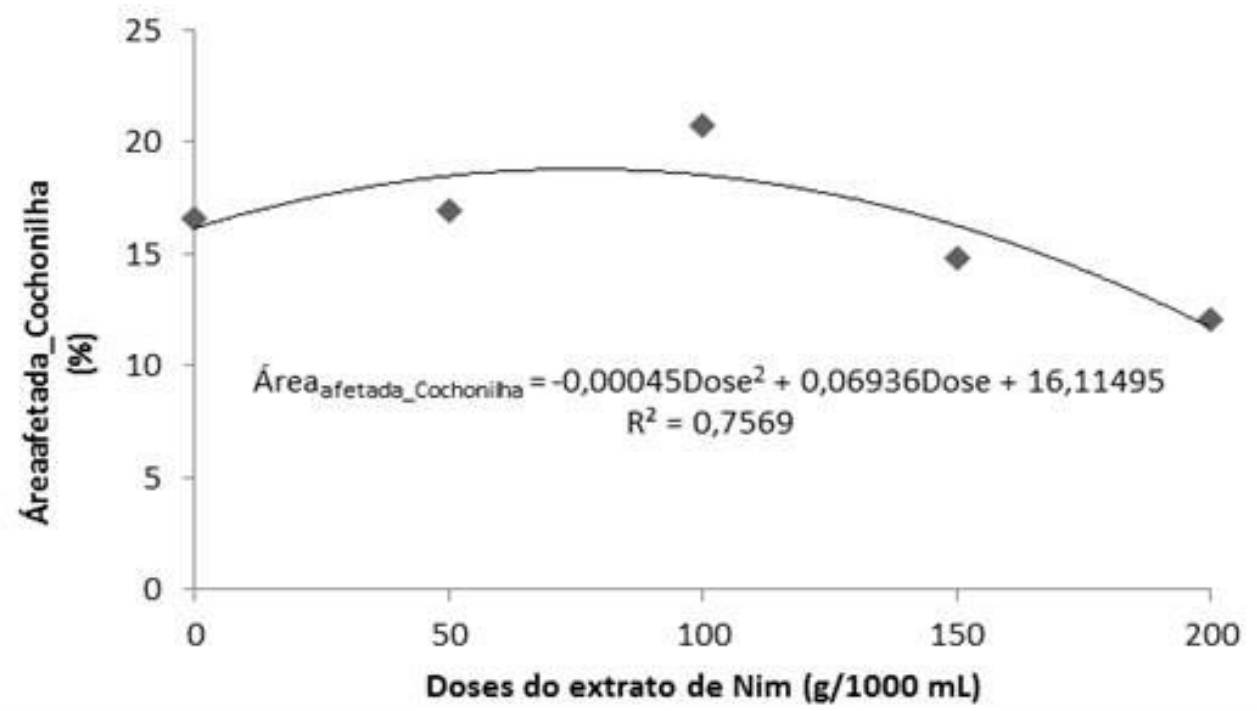

FIGURA 3- Área afetada pela cochonilha de escama em função das doses de extrato de nim.

$\mathrm{Na}$ Tabela 3, constam os dados das médias da área percentual infestada por cochonilha de escama na raquete quaternária. 
TABELA 3- Médias da área percentual infestada por cochonilha de escama na raquete quaternária, Barreira-CE, 2016.

\begin{tabular}{|c|c|c|c|c|c|}
\hline \multirow{3}{*}{ Fator $_{1}$} & \multicolumn{4}{|c|}{ Fator $_{2}$} & \multirow{3}{*}{ Médias } \\
\hline & 1 & 2 & 3 & 4 & \\
\hline & \multicolumn{4}{|c|}{$\begin{array}{l}\text { Área infestada por cochonilha/Área da raquete quaternária } \\
\text { total }(\%)\end{array}$} & \\
\hline 0 & $26,20 \mathrm{~A}$ & $13,22 \mathrm{~B}$ & $12,75 \mathrm{~B}$ & $14,05 \mathrm{~B}$ & 16,56 \\
\hline 50 & $24,74 \mathrm{~A}$ & $14,51 \mathrm{~B}$ & $10,82 \mathrm{~B}$ & $17,51 \mathrm{~B}$ & 16,90 \\
\hline 100 & $26,92 \mathrm{~A}$ & $16,68 \mathrm{~B}$ & $18,84 \mathrm{~B}$ & $20,57 \mathrm{AB}$ & 20,75 \\
\hline 150 & $21,97 \mathrm{~A}$ & $9,73 \mathrm{~B}$ & $13,01 \mathrm{~B}$ & $14,55 \mathrm{~B}$ & 14,82 \\
\hline 200 & $19,53 \mathrm{~A}$ & $7,62 \mathrm{~B}$ & $10,45 \mathrm{~B}$ & $10,56 \mathrm{~B}$ & 12,04 \\
\hline \multirow[t]{2}{*}{ Médias } & $23,87 \mathrm{~A}$ & $12,35 \mathrm{~B}$ & $13,18 \mathrm{~B}$ & $15,45 \mathrm{~B}$ & \\
\hline & \multicolumn{5}{|c|}{ Fator $_{2}$} \\
\hline \multirow[t]{2}{*}{ Fator 1} & & $2 / 1$ & $3 / 1$ & $4 / 1$ & \\
\hline & \multicolumn{5}{|c|}{ Reduções (\%) } \\
\hline 0 & & 49,54 & 51,33 & 46,37 & \\
\hline 50 & & 41,35 & 56,26 & 29,22 & \\
\hline 100 & & 38,03 & 30,01 & 23,58 & \\
\hline 150 & & 55,71 & 40,78 & 33,77 & \\
\hline 200 & & 60,98 & 46,49 & 45,92 & \\
\hline
\end{tabular}

A transformação $\operatorname{arcsen} \sqrt{\frac{x}{100}}$, foi empregada para se obter a Normalidade dos dados.

Fator $_{1}$ : parcela principal doses de extratos de Nim e Fator 2 : períodos de avaliação.

DMS do efeito condicionado para linhas $=6,97$ para classificação com letras maiúsculas. As médias seguidas pela mesma letra não diferem estatisticamente entre si. Foi aplicado o Teste Tukey ao nível de $5 \%$ de probabilidade.

O percentual de área infestada por cochonilha de escama em raquetes quaternárias da palma forrageira reduziu na segunda, terceira e quarta em relação à primeira avaliação em todas as doses do extrato aquoso de nim, com exceção a dose $100 \mathrm{~g}$ nim em pó para $1000 \mathrm{~mL}$, para a primeira avaliação com a quarta avaliação, conforme o teste de comparação de médias de Tukey. O extrato preparado com $200 \mathrm{~g}$ nim em pó para $1000 \mathrm{~mL}$ proporcionou as maiores reduções na área infestada por cochonilha de escama, nas datas de 2, 3 e 4 em relação a 1 (Tabela 3).

No presente estudo, a utilização de extratos das folhas de Nim para o controle da cochonilha de escamas em palma forrageira foi obtido maior controle com a dose de $200 \mathrm{~g}$ nim em pó para $1000 \mathrm{~mL}$ de água. Costa et al. (2016) estudaram para o controle da mosca minadora (Liriomyza sativae) em meloeiro, o extrato aquoso de sementes de nim nas concentrações de 15 e $20 \mathrm{~g}$ por $100 \mathrm{~mL}$, obtendo maior mortalidade de larvas desta praga. A planta de Nim é utilizada como inseticida natural para o controle de pragas por vários pesquisadores, através de obtenção de extratos e também de óleos de Nim que possui alguns compostos químicos importantes, sendo que o principal é a azadiractina, presente em folhas e frutos (MARTINEZ, 2002). Holtz et al. (2016) testaram extratos aquosos de pinhão-manso, com os componentes óleo, folha, casca do fruto, casca do caule e caule, e constataram efeito inseticida no controle da cochonilha-da-roseta, Planococcus citri na cultura do café. Braga et al. (2017), constataram controle de cochonilha em 
Hibiscus rosa-sinensis $\mathrm{L}$, com utilização de Capsicum frutescens L., associada ao álcool, fumo em rolo e sabão de coco.

O uso dessa planta como inseticida, tem um grande potencial para o controle da cochonilha, principalmente nas pequenas propriedades de produção de palma forrageira e com a identificação da melhor dose de extrato de folhas de nim no controle da cochonilha de escama representa uma opção direta de manejo da praga conforme a sua ação de controle. Para os pequenos agricultores, o extrato de nim no controle da cochonilha de escama pode representar uma forma econômica e ecologicamente segura para o manejo da cultura no campo.

\section{CONCLUSÃO}

O extrato aquoso de $200 \mathrm{~g}$ nim em pó para $1000 \mathrm{~mL}$ de água proporciona maior nível de controle da cochonilha de escama na palma forrageira graúda. A folha de nim seca triturada e diluída em água pode ser utilizada como inseticida natural no controle da cochonilha de escama.

\section{AGRADECIMENTOS}

Os autores agradecem ao Pesquisador Ph.D. da Embrapa Agroindústria Tropical, José Emilson Cardoso, por ceder o software APS ASSESS 2.0 e ao proprietário da fazenda Bom Sucesso, Barreira-CE por disponibilizar o plantio de palma forrageira para realização da pesquisa.

\section{REFERÊNCIAS}

ALBUQUERQUE, M. B.; GARCIA NETO, S.; ALMEIDA; D. J.; MALTA, A. O. Efeito do extrato aquoso das folhas de nim indiano (Azadirachta indica) sobre o crescimento inicial de plantas daninhas. Gaia Scientia, v.9, n.1, p.1-6, 2015. Disponível em: http://www.periodicos.ufpb.br/ojs/index.php/gaia/article/view/19211.

BRAGA, G. S.; COSTA, M. A. G.; ROCHA, A. N. Formulação orgânica eficiente para controle de Cochonilha (Dactylopius coccus) em plantas ornamentais: estudo de caso em Hibiscus rosa- sinensis L. Revista Fitos, v. 11, n. 1, p. 49-53, 2017. Disponível em: https://www.arca.fiocruz.br/bitstream/icict/21130/2/gilberto_silva_et_all.pdf._ DOI 10.5935/2446-4775.20170014.

BORSONARO, M. T.; SENÔ, K. C. A.; IAMAGUTI, P. S.; NEVES, M. C.T.; SILVA, P.T. Extrato aquoso de folhas de Azadirachta indica A. Juss no controle de Sitophilus zeamais Mots. (Coleoptera: curculionidae) em milho armazenado. Nucleus, v.10, n.1, p.161-168, 2013. DOI: 10.3738/1982.2278.858.

CAVALCANTE, L. A. D.; SANTOS, G. R. A.; SILVA, L. M.; FAGUNDES, J. L.; SILVA, M. A. Respostas de genótipos de palma forrageira a diferentes densidades de cultivo. Revista Pesquisa Agropecuária Tropical, v. 44, n. 4, p. 424-433, 2014. Disponível em: http://www.scielo.br/pdf/pat/v44n4/v44n4a10.pdf.

COSTA, E. M.; TORRES, S. B.; FERREIRA, R. R.; SILVA, F. G.; ARAUJO, E. L. Extrato aquoso de sementes de nim no controle de Liriomyza sativae (Diptera: Agromyzidae) em meloeiro. Revista Ciência Agronômica, v. 47, n. 2, p. 401-406, abr-jun, 2016. Disponível em: http://www.scielo.br/pdf/rca/v47n2/1806-6690-rca-4702-0401.pdf. DOI: 10.5935/1806-6690.20160048. 
HOLTZ, A. M.; FRANZIN, M. L.; PAULO, H. H.; BOTTI, J. M. C.; MARCHIORI,J.J.P.; PACHECO, E.G. Controle alternativo de Planococcus citri (Risso, 1813) com extratos aquosos de pinhão-manso. Arquivos do Instituto Biológico, v.83, p.1-6, 2016. Disponível em: http://www.scielo.br/pdf/aib/v83/1808-1657-aib-83e1002014.pdf. DOI: 10.1590/1808-1657001002014.

IPECE - Instituto de Pesquisa e Estratégia Econômica do Ceará, Perfil básico municipal - Barreira. Fortaleza, CE, p. 18, 2017. Disponível em: http://www.ipece.ce.gov.br/perfil_basico_municipal/2017/Barreira.pdf.

LAMARI, L. ASSESS 2.0: Image analysis software for disease quantification. Saint Paul: APS, 2008. 125p.

LIMA, G. F. C.; WANDERLEY, A. M.; GUEDES, F. X.; REGO, M. M. T.; DANTAS, F. D. G.; SILVA, J. G. M.; NOVAES, L. P.; AGUIAR, E. M. Palma Forrageira Irrigada e Adensada: uma Reserva Forrageira Estratégica para o Semiárido Potiguar. Parnamirim: EMPARN, 2015. 62 p.: il. - (EMPARN Documentos; 45). Disponível em: http://adcon.rn.gov.br/ACERVO/EMPARN/DOC/DOC000000000132235.PDF.

LOUREIRO, S. M. S.; FERNANDES, A. L. L.; SILVA, A. M. S.; SILVA, A. C.; QUEIROZ, G. A.; ALMEIDA, M. L. F.; ALBUQUERQUE, M. T.; SANTOS, M. D.; RAMOS, S. L. P. Produtos alternativos para o controle de pragas e doenças na agricultura. COHIDRO-Companhia de Desenvolvimento de Recursos Hídricos e Irrigação de Sergipe. 2a edição revisada, p.42, 2016. Disponível em: http://cohidro.se.gov.br/wp-

content/uploads/2017/11/produtos_alternativos_para_o_controle_de_pragas_e_doen cas_na_agricultura.pdf.

MARTINEZ, S. S. O NIM - Azadirachta indica: natureza, usos múltiplos, produção. Londrina: IAPAR, 2002, 142p

OLIVEIRA, L. B. Uso e manejo da água na região semiárida do nordeste do Brasil. Anais da Academia Pernambucana de Ciência Agronômica, Recife, v. 11, p.5064 , 2014.

Disponível: http://www.journals.ufrpe.br/index.php/apca/article/view/1095/890.

SANTOS, P. L.; PRANDO, M. B.; MORANDO, R.; PEREIRA, G. V. N.; KRONKA, A. Z. Utilização de extratos vegetais em proteção de plantas. Enciclopédia Biosfera, Centro Científico Conhecer - Goiânia, v.9, n.17; p.2562-2576, 2013. Disponível em: http://www.conhecer.org.br/enciclop/2013b/CIENCIAS\%20AGRARIAS/utilizacao\%20 de\%20 Extratos.pdf.

SILVA, F.A. S.; AZEVEDO, C. A. V. The Assistat Software Version 7.7 and its use in the analysis of experimental data. African Journal of Agricultural Research, v.11, n.39, p.3733-3740, 2016. Disponível em: https://academicjournals.org/journal/AJAR/article-full-text-pdf/5E8596460818. DOI: 10.5897/AJAR2016.11522. 
SILVA, C. D.; SANTOS, N. M. R.; COSTA, P. V.; MARTINS, M. T. C. S. Dactylopius opuntiae: Impactos causados e métodos alternativos utilizados em Opuntia ficusindica no município de Santo André-PB. Scire Revista Acadêmico-Científica, v.2, n.1, p.1-13, 2013. Disponível em: http://www.revistascire.com.br/artigo/2013/FEVEREIRO/MetodoAlternativoCimaraFe vereiro2013.pdf.

SILVA, L. M.; FAGUNDES, J. L.; VIEGAS, P. A. A.; MUNIZ, E. N.; RANGEL, J. H. A.; MOREIRA, A. L.; BACKES, A. A. Produtividade da palma forrageira cultivada em diferentes densidades de plantio, Ciência Rural, v.44, n.11, p.2064-2071, 2014. Disponível em: http://www.scielo.br/pdf/cr/v44n11/0103-8478-cr-44-11-02064.pdf. doi.org/10.1590/0103-8478cr20131305.

VIEIRA, M. R.; PERES, L. S. Uso de extrato foliar de nim, Azadirachta indica A. Juss, para o controle do pulgão Brevicoryne brassicae (L.) em cultivos de brócolis. Cultura Agronômica, Ilha Solteira, v.26, n.4, p.492-501, 2017. Disponível em: http://ojs.unesp.br/index.php/rculturaagronomica/article/view/2348/1831. 